\title{
Summer mean temperature variation from 1710-2005 inferred from tree-ring data of the Baimang Snow Mountains, northwestern Yunnan, China
}

\author{
ZongShan $\mathrm{Li}^{1,2}$, Chun Ming Shi ${ }^{1,3}$, Yongbo Liu ${ }^{1}$, Jinlong Zhang ${ }^{1}$, Qibing Zhang ${ }^{1, *}$, \\ Keping $\mathrm{Ma}^{1}$
}

${ }^{1}$ State Key Laboratory of Vegetation and Environmental Change, Institute of Botany, Chinese Academy of Sciences, Beijing 100093, PR China

${ }^{2}$ State Key Laboratory of Urban and Regional Ecology, Research Center for Eco-Environmental Science, Chinese Academy of Sciences, Beijing 100085, PR China

${ }^{3}$ Laboratoire des Sciences du Climat et de l'Environnement, UMR 1572, IPSL/CEA/CNRS/UVSQ, 7 Bat 701, L'Orme des Merisiers, CEA Saclay, 91191 Gif sur Yvette Cedex, France

\begin{abstract}
The tree-ring chronologies of Abies georgei Orr were developed for 3 sites at different elevations: the southern $(2750 \mathrm{~m})$, middle $(3050 \mathrm{~m})$, and northern $(3400 \mathrm{~m})$ parts of the Baimang Snow Mountains in northwestern Yunnan Province, China. The climate-growth response analysis indicated that trees at different elevations respond differently to environmental changes. The radial growth of trees found at the middle and high elevation sites was determined by temperature variables (mean, maximum, and minimum temperatures), particularly during the summer season (June to August), while moisture availability (precipitation and relative humidity) during spring (in March) was the crucial climate factor for tree growth at the low elevation site. The linear climate-growth model derived from the composite chronology of the 2 high elevation sites was verified with independent data from 1958 to 2005, and accounted for $33.4 \%$ of the mean temperature variation during summer (June to August). Based on this model, summer minimum temperature variations were reconstructed for the past $296 \mathrm{yr}$. The reconstruction revealed that cool climates mainly occurred in 1732-1743, 1758-1780, 1791-1824, 1836-1847, 1853-1862, 1908-1929, 1964-1976, and 1979-1993, while warm climates prevailed in 1718-1731, 1744-1756, 1781-1790, 1825-1835, 1883-1907, 1930-1963, and 1995 to present. Spectral analysis of the reconstruction using the multi-taper method (MTM) indicated the existence of some multidecadal (about $70 \mathrm{yr}$ ) and bidecadal (about 20 yr) cycles, which might correspond to the related cycles of solar activity, and significant peaks at about 2 to 8 yr, in agreement with the spectral mode of El Niño Southern Oscillation (ENSO)-type variability.
\end{abstract}

KEY WORDS: Summer temperature - Climate reconstruction · Tree-ring $\cdot$ Northwestern Yunnan

\section{INTRODUCTION}

Northwestern Yunnan Province, which is located in the central Hengduan Mountains, forms the southeastern rim of the Tibetan Plateau and is strongly affected by the South Asian summer monsoon (Charles et al. 1997, Kumar et al. 1999). As a result, improving knowledge of the long-term climate changes and potential large-scale trends in northwestern Yunnan is of great importance for future predictions of large-scale synoptic patterns, such as Asian monsoon dynamics (Allan et al. 1996, Cook et al. 2010). However, meteorological records are limited in northwestern Yunnan, so highresolution proxy data, such as tree rings, can add invaluable information on the climate history of this region. 
Tree-ring measurements provide a particularly valuable indicator of climatic history as they offer precise dating, extensive spatial availability, and climatologically high sensitivity (Fritts 1976, Schweingruber 1996). Tree-ring data play an important role in reconstructing the climate variability of the Northern Hemisphere and have been integrated worldwide into research on global change (Esper et al. 2002, Mann et al. 2008). The coniferous forests in northwestern Yunnan are ancient and diverse (Wu 1987), offering a compelling opportunity to explore tree-ring data, but few dendroclimatological studies have been conducted in this region. The earliest such study in this region was carried out at Haba Snow Mountains, in which Wu et al. (1988) reported a tree-ring chronology indicative of air temperature during the last $400 \mathrm{yr}$ and suggested the existence of similar variations in the Tibetan Plateau. Based on the tree-ring data of the central Hengduan Mountains, variability in summer temperatures and spring droughts during the past several centuries have also been reconstructed (Fan et al. 2008, 2009a, Li et al. 2011a). In this study, we investigate the tree-ring data of fir (Abies georgei Orr) forests at 3 different elevation sites in the Baimang Snow Moun. tains in northwestern Yunnan Province, China. With these tree-ring data, we describe the relationships of tree growth to climate, enabling us to develop a tem. perature reconstruction covering the past 3 centuries. This study expands the knowledge of climatic variability in this ecologically complex region.

\section{MATERIALS AND METHODS}

\subsection{Study area}

The study area is located on Baimang Snow Mountains $\left(27.47^{\circ} \mathrm{N}, 98.57^{\circ} \mathrm{E}\right.$ to $28.36^{\circ} \mathrm{N}, 99.21^{\circ} \mathrm{E}$ ), belonging to Three Parallel River Natural World Heritage Site (http://whc.unesco.org/en/list/1083) in northwestern Yunnan Province, China (Fig. 1). This region is characterized by a chain of mountains and rivers crossing from north to south (Xu \& Wilkes 2004). Three major Asian rivers, the Yangtze (Jinshajiang), Mekong (Lancangjiang), and Salween (Nujiang) Rivers, converge within a $90 \mathrm{~km}$ corridor and carve deep parallel gorges (Gaetz 2002). The resulting spectacular gorges rise from river valleys $(1500 \mathrm{~m})$ to the highest glaciated peaks $(6740 \mathrm{~m})$ within a distance of $20 \mathrm{~km}$ or less. The varied geology, topography, and climate of northwestern Yunnan combine to create one of the richest temperate regions of the world in terms of biodiversity (Myers et al. 2000, Ying 2001, Xu \& Wilkes 2004). Abies georgei Orr is widely distributed at the subalpine vegetation zone between 2500 and $4200 \mathrm{~m}$ in northwestern Yunnan. It is also one of the main climax constituents of subalpine cold coniferous forests in the Tibetan Plateau (Liu et al. 2001). A. georgei generally

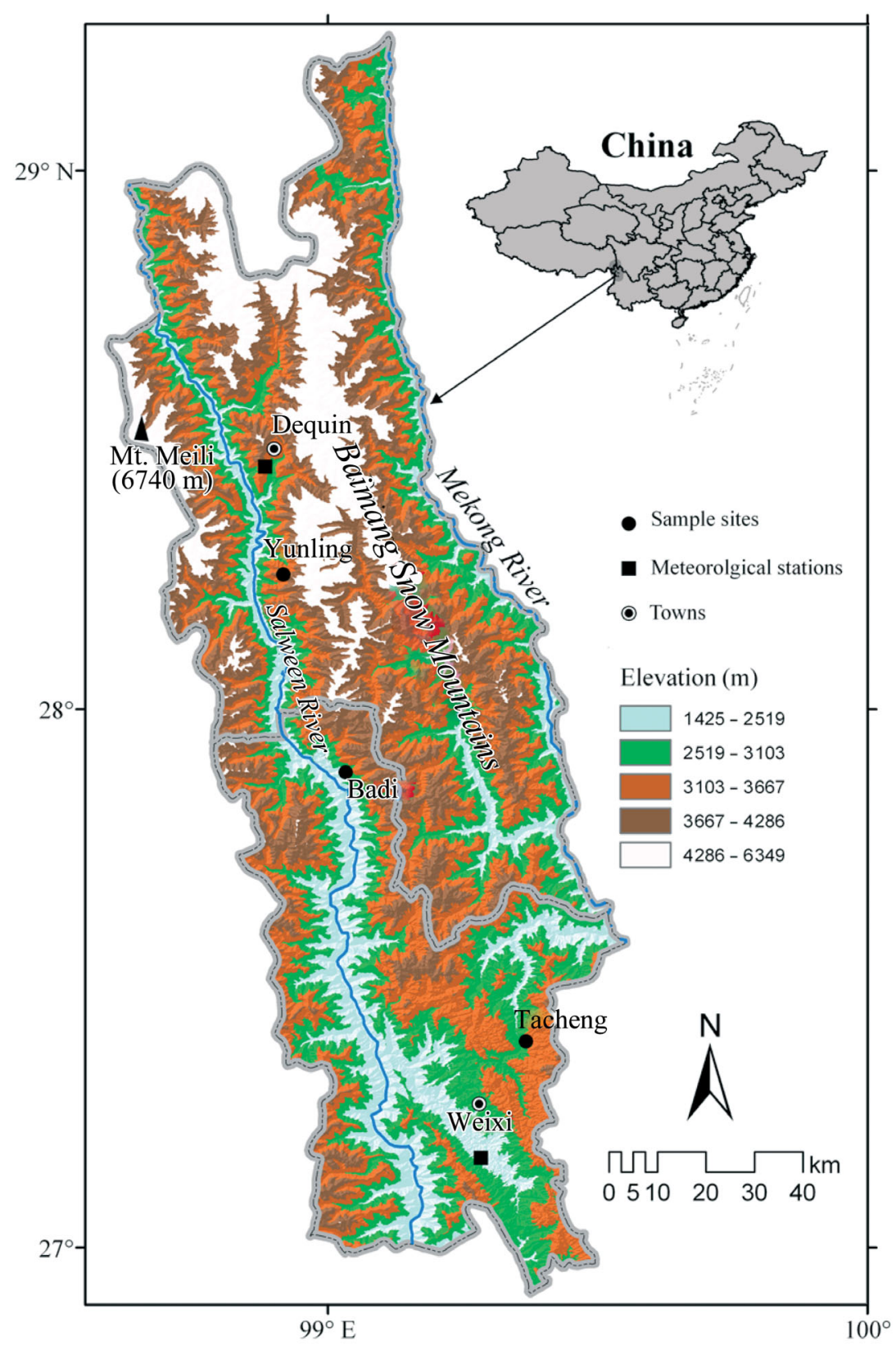

Fig. 1. Tree-ring sample sites and meteorological stations in the Baimang Snow Mountains, northwestern Yunnan, China 
has strong shade tolerance, grows on the cold, shady sides of mountains, and can reach heights of $30 \mathrm{~m}$. A. georgei is often found with with certain species of fir (A. georgei var. smithii, A. forrestii and A. squamata), spruce (Picea likiangensis), and larch (Larix potaninii var. macrocarpa) in mixed coniferous forests (Wong et al. 2010).

The climate of the region is strongly dominated by the South Asian monsoons from May to October, with summer rains mainly originating from monsoonal air masses flowing from the Indian Ocean and Bay of Bengal, whereas the climate in winter is generally dry under the control of the continental air masses of the Central Asian high pressure cell (Ma et al. 1993, Xu et al. 2003). According to the meteorological stations in Deqin and Weixi, the mean annual temperature in the study area is $8.31^{\circ} \mathrm{C}$, with a mean temperature of $15.37^{\circ} \mathrm{C}$ in July and $0.6^{\circ} \mathrm{C}$ in January. Mean annual total precipitation is $806 \mathrm{~mm}$, with a maximum monthly ers approximately May to August, during which about $70 \%$ of the average annual precipitation is received.

\subsection{Sampling and preparation}

The tree-ring cores of living Abies georgei were collected from the west slopes of the Baimang Snow Mountains at 3 different elevations: the Yunling (3400 m), Badi $(3050 \mathrm{~m})$, and Tacheng $(2750 \mathrm{~m})$ sites (abbreviated as YL, BD, and TC, respectively) (Table 1). The 3 sites are located in the northern, middle, and southern parts of the Baimang Snow Mountains, respectively (Fig. 1). The sampling sites are not disturbed by human activity. To minimize non-climatic influences on treering growth and maximize the ages of the sampled sum of $147 \mathrm{~mm}$ in July (Fig. 2). The growing season cov-

trees, only trees with the largest diameters that had no obvious injury or disease were sampled. A minimum of 40 trees were selected at each site, and for each tree, 1 increment core was extracted at chest height. In total, increment cores were extracted from 131 A. georgei trees in the sample sites with an increment borer.

The tree-ring samples were processed following standard dendrochronological practices (Stokes \& Smiley 1968), including air drying, mounting, and sanding in the laboratory. The tree-ring series were rigorously crossdated and measured to a precision of $0.001 \mathrm{~mm}$ using a Velmex tree-ring measurement system. The quality of the cross-dating was checked by the COFECHA program, which can ensure exact dating for annual ring width by correcting the potential bias of missing rings

Table 1. Summary statistics for the tree-ring width chronologies of Abies georgei from 3 different elevation sites in the Baimang Snow Mountains, northwestern Yunnan Province, China. MRW: mean tree width; SD: standard deviation; MS: mean sensitivity; AC1: autocorrelation order 1; Rbar: mean inter-series correlation; SNR: signal-to-noise ratio; EPS: express population signal; VFE: variance in first eigenvector

\begin{tabular}{|lccc|}
\hline Location & Tacheng & Badi & Yunling \\
(Lat./ Long.) & $\begin{array}{c}27.38^{\circ} \mathrm{N}, \\
99.37^{\circ} \mathrm{E}\end{array}$ & $\begin{array}{c}27.88^{\circ} \mathrm{N}, \\
99.03^{\circ} \mathrm{E}\end{array}$ & $\begin{array}{c}28.25^{\circ} \mathrm{N}, \\
98.92^{\circ} \mathrm{E}\end{array}$ \\
\hline Altitude (m) & 2750 & 3050 & 3400 \\
Chronology length & $1800-2005$ & $1670-2005$ & $1754-2005$ \\
Number of cores & 32 & 37 & 44 \\
MRW (mm) & 1.755 & 1.060 & 1.038 \\
SD & 0.876 & 0.622 & 0.540 \\
MS & 0.238 & 0.226 & 0.201 \\
AC1 & 0.528 & 0.689 & 0.811 \\
Rbar & 0.386 & 0.469 & 0.494 \\
SNR & 4.434 & 7.140 & 8.459 \\
EPS & 0.819 & 0.877 & 0.894 \\
VFE (\%) & 20.9 & 25.8 & 28.6 \\
\hline
\end{tabular}
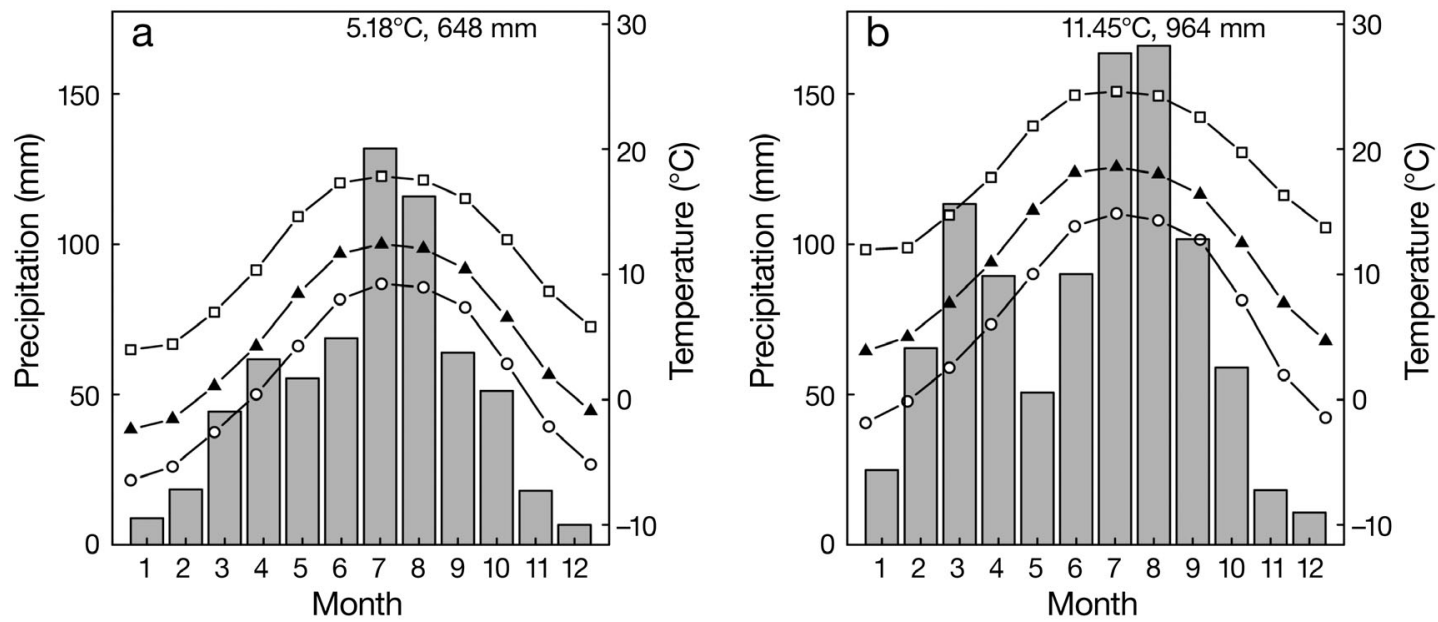

Fig. 2. Monthly variation of total precipitation (bars) and maximum (O), mean ( $\square$ ) and minimum (A) temperatures for (a) Deqin $(3485 \mathrm{~m})$ and (b) Weixi $(2325 \mathrm{~m})$ meteorological stations, calculated for 1958 to 2005. Mean annual temperature and precipitation are given at top-right of panel 
and dating errors (Holmes 1983); 18 cores of poor quality (e.g. fragmented, rotten, or below the $95 \%$ confidence limit of cross-dating with the master series) were discarded from further analyses. The remaining 113 increment cores (32 cores for TC, 37 cores for $\mathrm{BD}$, and 44 cores for YL) were used in this analysis.

\subsection{Chronology development}

As is standard to most dendroclimatic studies, the raw ring-width measurements of each site were detrended and standardized to remove long-term biological growth trends while preserving growth variations that were likely related to climate variability (Fritts 1976, Cook 1987). Prior to standardization, a data adaptive power transformation based on the local mean and standard deviation was applied to reduce the potential end-fitting bias of tree-ring series (Cook \& Peters 1997). Conservative detrending methods, or the use of negative-exponential curves or straight lines with any slopes, were employed in the standardization process in order to limit the loss of low-frequency information (Cook \& Kairiukstis 1990). A cubic smoothing spline with a $50 \%$ frequency-response cut-off equal to $67 \%$ of the length of the series was also used in a few cases when anomalous growth trends occurred (Cook \& Peters 1981). Deviations of the individual measurements from the detrending curves were calculated as residuals, and dimensionless indices were averaged to form the site chronologies by computing a biweight robust mean in order to reduce the influence of outliers (Cook \& Kairiukstis 1990). To reduce the effect of higher standard deviations in weakly replicated portions of the chronology, the variance of the chronology was stabilized (Osborn et al. 1997). The so-called standard chronology was retained for analysis to maximize low-frequency variance potentially due to climate.

We quantitatively evaluated chronology signal strength using 2 common measures: (1) the expressed population signal or EPS (Wigley et al. 1984), which indicates how well the site chronology estimates a theoretically infinite population; and (2) Rbar (Cook \& Kairiukstis 1990), which measures the average correlation among ring-width series. Both EPS and Rbar were calculated in a $30 \mathrm{yr}$ running window with $15 \mathrm{yr}$ overlaps along the chronology. The reliable parts of the chronologies were identified using EPS and, consistent with the recommended threshold of 0.85 (Wigley et al. 1984), chronology sections with $<5$ series were removed. Several other descriptive statistics were also estimated to characterize the site chronologies, including mean sensitivity (MS) and signal-to-noise ratio (SNR) to assess the high-frequency variation of the tree-ring width, first order autocorrelation (AC1) to detect the persistence of the site chronologies, and the variance in the first eigenvector (VFE) to estimate the strength of observed common signals among the trees.

\subsection{Data analysis}

For the calibration of tree-ring data, the climate data from 2 meteorological stations (Deqin and Weixi) near our sample sites were used; these data were provided by the China Meteorological Data Sharing Service System (http://cdc.cma.gov.cn/). The 2 stations both had records for 1958 to 2005. The TC site was near the Weixi station $(2325 \mathrm{~m})$, while the BD and YL sites were near the Deqin station $(3485 \mathrm{~m})$. The climate variables of the 2 stations included the monthly mean (Tmean), minimum (Tmin), and maximum (Tmax) temperatures, monthly total precipitation (PRE), and monthly relative humidity (RH). Climate-growth relationships were determined using correlation analyses in the DendroClim2002 program (Biondi \& Waikul 2004). Common period (1958 to 2005) correlations were calculated on an 11-mo dendroclimatic year beginning in October of the calendar year preceding radial growth and ending in August of the radial growth year. The 'year' included several months leading up to the growth season, which allows for the identification of prior-year climatic preconditioning effects on radial growth (Fritts 1976).

The leave-one-out cross-validation method was employed to assess the temporal stability of the regression model for climate reconstruction because the available meteorological data set was too short to carry out a robust split-sample calibration (Michaelsen 1987). Verification statistics included the Pearson's correlation coefficient ( $\mathrm{r}$, reduction of error (RE), sign test (ST), and product mean test (Pmt), all of which are commonly used in dendroclimatology (Fritts 1976, Cook et al. 1994). The RE statistic tests whether the model provides a more skillful estimate than the mean climatology of the calibration period, with a positive value indicating skill of the regression model. The ST and Pmt statistics describe how well the predicted values match the actual data (Fritts 1976, Wilson et al. 2006). Additionally, the multi-taper method (MTM) spectral analysis (Mann \& Lees 1996) was further employed to examine frequency domains of the reconstruction series.

\section{RESULTS}

\subsection{Chronology statistics}

The chronologies covered the past 206 to $336 \mathrm{yr}$, with mean segment length (MSL) ranging from 148 (TC) to 

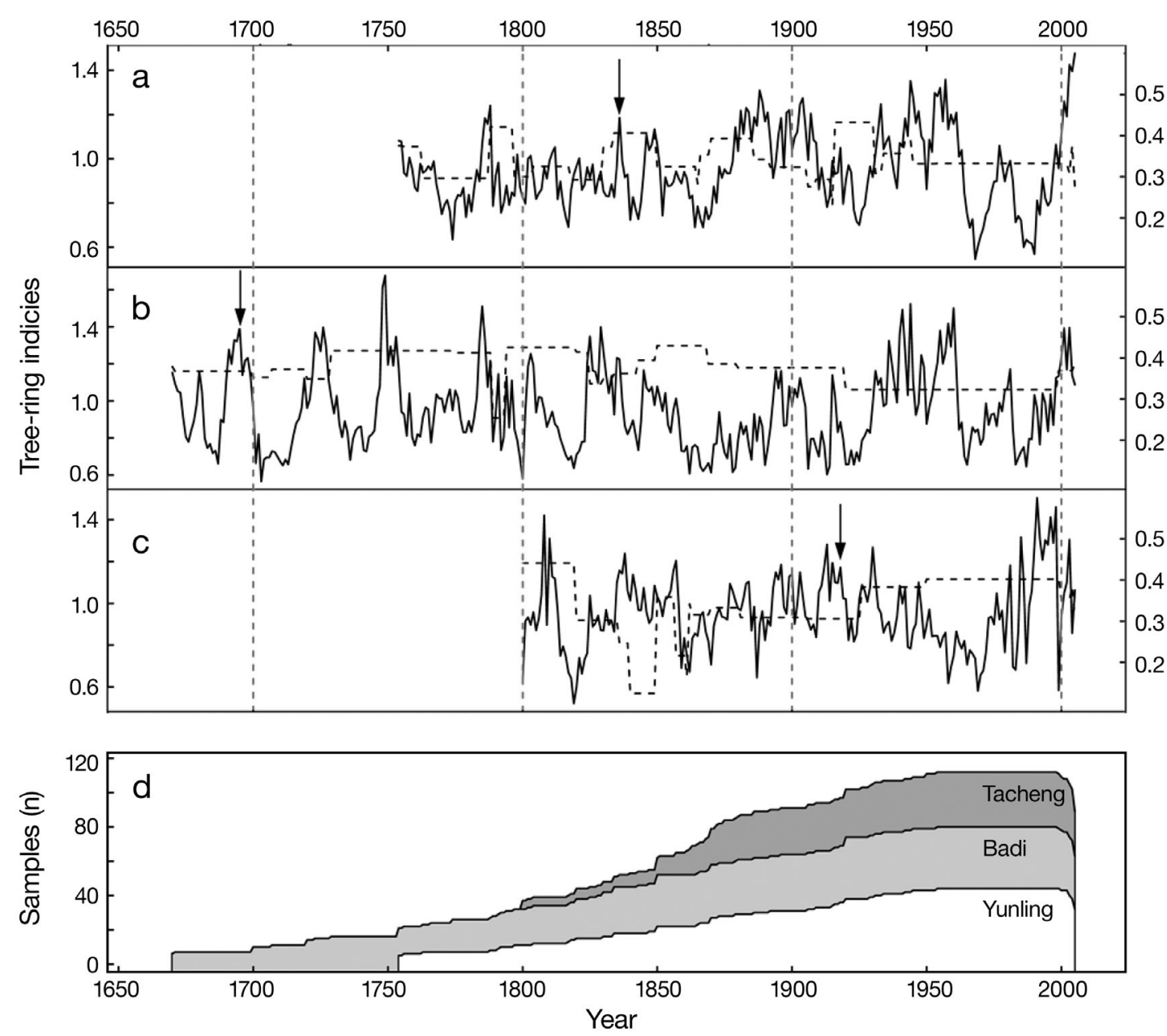

Fig. 3. Tree-ring width chronologies for 3 forest sites of the Baimang Snow Mountains, northwestern Yunnan Province, China. (a) Tacheng site chronology at a low elevation $(2750 \mathrm{~m})$, (b) Badi site chronology at a middle elevation (3050 m), (c) Yunling site chronology at a high elevation $(3400 \mathrm{~m})$, (d) sample count over time, with separately identified counts for the 3 chronologies.

Black dashed line: moving Rbar (mean inter-series correlation); arrow: year with EPS (express population signal) $>0.85$

233 yr (BD) (Fig. 3). The EPS attained the generally recommended threshold value of 0.85 in 1915 for the YL site, 1830 for the TC site, and 1695 for the BD site. Although the running Rbar displayed high variability over time, this statistic was rather stable during the robust intervals (EPS > 0.85) of the chronologies (0.412 to 0.604 for TC, 0.309 to 0.657 for $\mathrm{BD}$, and 0.289 to $0.665 \mathrm{YL}$ ). In comparison to the 2 chronologies at high elevations (YL, BD), the tree-ring series at a low elevation (TC) had high mean ring width and standard deviation values. MS, characterizing the year-to-year variability in tree-ring records, ranged from 0.201 to 0.238 , whereas the SNR in tree rings ranged from 4.434 to 8.459. The value of AC1 ranged from 0.528 to 0.811 , indicating that the ringwidth data had some autocorrelation that was likely caused by biological feedback (Fritts 1976). The relatively high level of VFE (20.9 to $28.6 \%$ ) indicated strong common signals among the trees constituting the mean chronology. Therefore, our tree-ring chronologies provided a robust estimate of the mean of tree growth and are suitable for dendroclimatological analysis.

\subsection{Climate-growth response}

The correlation analysis showed that temperature (Tmean, Tmin, and Tmax) was generally the main factor influencing tree growth at the high (YL) and middle (BD) elevation sites (Fig. 4), and the highest peaks of correlations were found during the summer season (June to August), especially in July ( $r=0.318$ to 0.458, $\mathrm{p}<0.01$ ) and August ( $\mathrm{r}=0.409$ to $0.565, \mathrm{p}<0.01)$. Temperatures (Tmean, Tmin, and Tmax) in April also had a positive influence ( $r=0.359$ to $0.477, \mathrm{p}<0.01$ ) on radial growth, and the winter (prior November to current February) Tmax appeared to be another relevant cli- 
matic factor limiting tree growth. Compared with the predominant impact of temperature, the influences of PRE and RH were much weaker. In contrast, the chronology at the low (TC) elevation site had signifi-
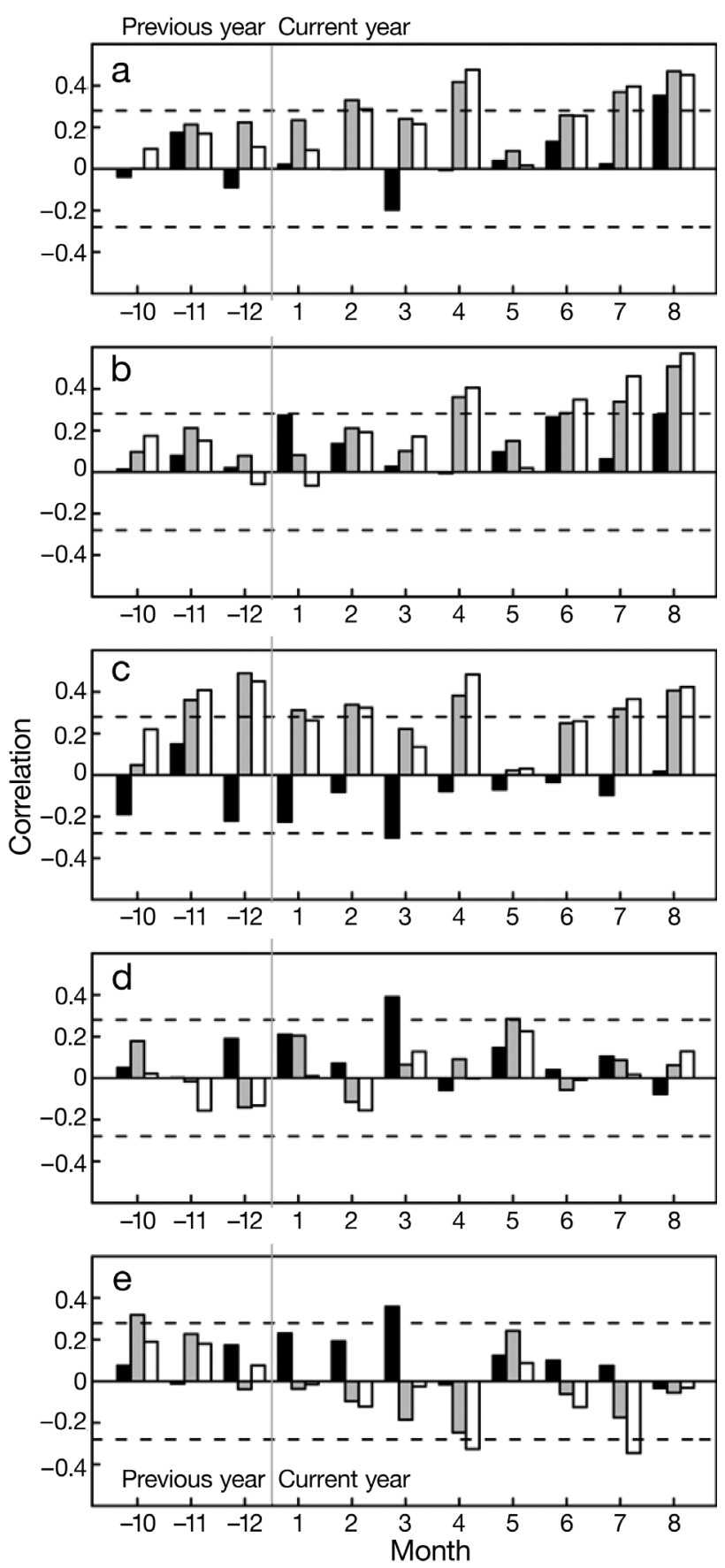

Fig. 4. Correlations between monthly climatic variables for the tree-ring chronologies of the lower (black, $2750 \mathrm{~m}$, Tacheng), middle (grey, $3050 \mathrm{~m}$, Badi), and higher (white, $3400 \mathrm{~m}$, Yunling) elevation sites, respectively. (a) Mean temperature, (b) minimum temperature, (c) maximum temperature, (d) precipitation and (e) relative humidity. Horizontal dashed lines: significant effect $(p<0.05)$ cantly positive correlations with PRE ( $\mathrm{r}=0.388, \mathrm{p}<$ $0.01)$ and $\mathrm{RH}(\mathrm{r}=0.356, \mathrm{p}<0.01)$ in March, while temperature had a weaker influence on radial growth in comparison to the middle and high elevation sites.

The two high elevation site chronologies (BD, YL) had similar responses to the climatic variables concerning climate-growth relations (Fig. 4). Further, considering the high percentage of similarity in growth variations between the 2 sites $(\mathrm{r}=0.515$ for their common period: 1754 to $2005, p<0.01$ ), the tree-ring series of the 2 sites could be merged to develop one robust composite chronology. Following the procedure outlined in Section 2.3 of this paper, 81 cores of the 2 sites were standardized and combined to develop a single ringwidth chronology capturing the regional climate signal (Fig. 5). The MSL, or the average number of rings per core in the composite chronology, was 294 yr with a range of 52 to $425 \mathrm{yr}$. Consequently, the low-frequency variance due to climate in the composite chronology was relevant in multidecadal scales. However, the conservative standardization method used to develop this chronology removes the overall slope of the chronologies, thus limiting our ability to consider multi-century and longer timescale changes (Cook et al. 1995). The running Rbar and EPS were used together to evaluate the quality of the composite chronology. The reliable portion of the chronology extended from 1710 to 2005

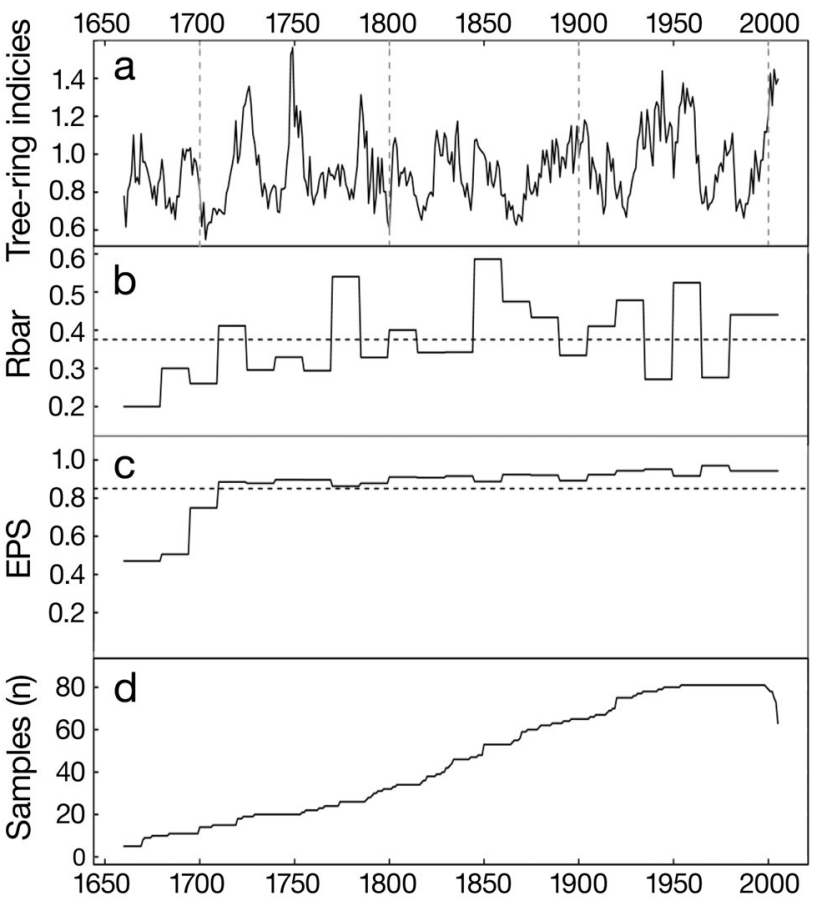

Fig. 5. Composite chronology based on tree-ring cores at the 2 higher elevation sites (Badi and Yunling). (a) Chronology series, (b) mean inter-series correlation (Rbar; dashed line: mean), (c) express population signal (EPS; dashed line: 0.85 cut-off value), and (d) changing sample size over time 


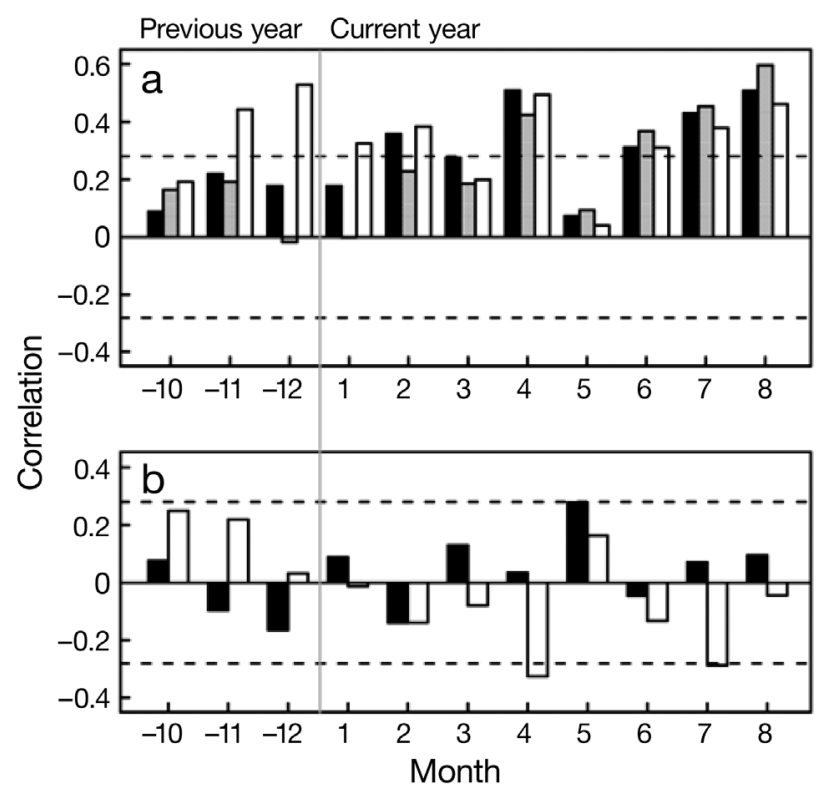

Fig. 6. Correlations of the composite chronology with monthly climatic variables. (a) Correlations with mean temperature (black), minimum temperature (grey), and maximum temperature (white); (b) correlations with precipitation (black) and relative humidity (white). Horizontal dashed lines: significant effect $(\mathrm{p}<0.05)$

with an EPS > 0.85 (Fig. 5c), and the mean Rbar during this period was 0.449 (Fig. 5b).

Correlation analysis between the composite chronology and climate data indicated that temperature (Tmean, Tmin, and Tmax) was a main factor influenc-

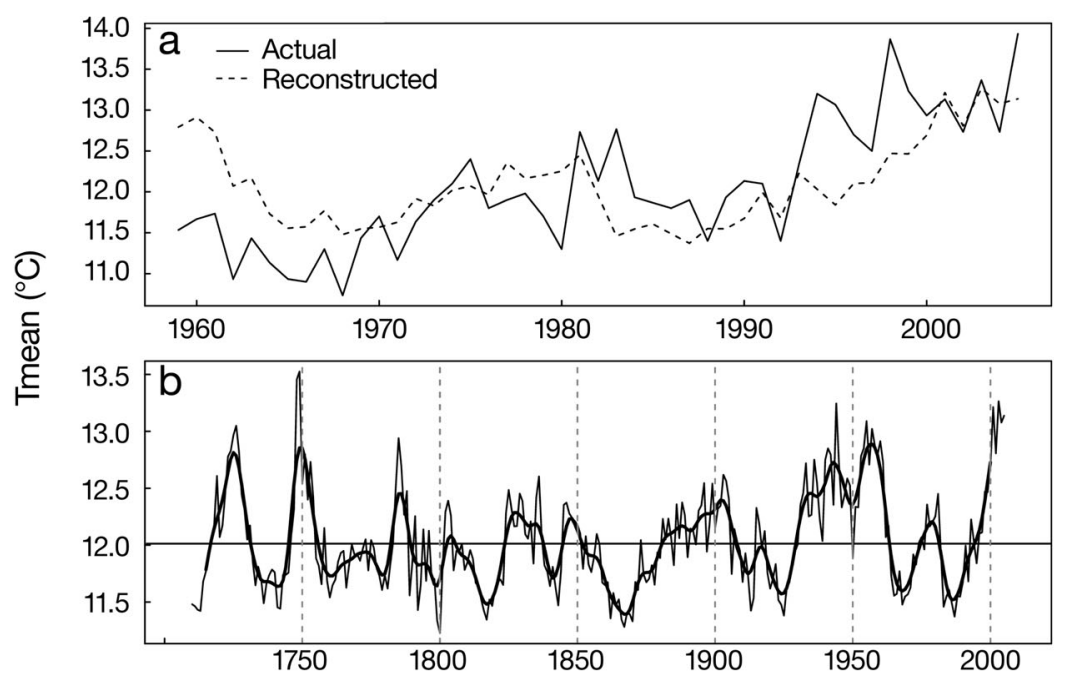

Fig. 7. Climate reconstruction in the Baimang Snow Mountains, northwestern Yunnan Province, China. (a) Comparison of actual and reconstructed summer (June to August) mean temperatures (Tmean) from 1956 to 2005, (b) tree-ring reconstruction (thin line) of summer Tmean plotted annually from 1710 to 2005 and its smoothed series (bold line) with an $11 \mathrm{yr}$ low-pass filter
Table 2. Leave-one-out cross-validation statistics of the climategrowth model for climate reconstruction in the Baimang Snow Mountains, northwestern Yunnan Province, China. r: correlation coefficient calculated between the actual and estimated data; $R^{2}$ : square of the correlation coefficient; $R_{a d j}^{2}: R^{2}$ value adjusted to take account of the effective number of predictors; $R E$ : reduction of error statistic; ST: sign test; PMT: $t$-value derived using the product mean test. ${ }^{*}$ significant at $\mathrm{p}<0.05$

\begin{tabular}{|ccccccc|}
\hline & $\mathrm{r}$ & $\mathrm{R}^{2}$ & $\mathrm{R}_{\mathrm{adj}}^{2}$ & $\mathrm{RE}$ & $\mathrm{ST}$ & $\mathrm{PMT}$ \\
\hline Calibration & 0.578 & $0.334^{*}$ & $0.317^{*}$ & - & - & - \\
Verification & 0.535 & $0.287^{*}$ & $0.274^{*}$ & 0.276 & $32+/ 14-^{*}$ & $3.987^{*}$ \\
\hline
\end{tabular}

ing radial growth (Fig. 6), and most of the significant correlations occurred in the summer months (June to August), followed by the correlations of temperature (Tmean, Tmin, and Tmax) in the spring (April) and Tmax in the winter (previous November to current February). Additionally, the composite chronology had no clear association with PRE or RH. This result generally confirms the climate-growth relationships derived from individual chronologies. Seasonally averaged climate data may be more representative of climate conditions than data from one single month (Cook et al. 1999). Therefore, we tested different seasonal combinations of climate variables for reconstruction. Finally, the mean temperature in summer (June to August) was considered as a candidate predictor.

\subsection{Summer mean temperature reconstruction}

A linear regression model $(y=2.421 x$ $+9.748)$ was developed to reconstruct the summer Tmean history for the Baimang Snow Mountains in northwestern Yunnan Province, China (Fig. 7 ). In the data on tree rings and temperature (1958 to 2005), the reconstruction accounted for $33.4 \%$ of the actual temperature variance (Table 2). As shown in Fig. $7 \mathrm{a}$, our reconstruction paralleled the general tendency of the observed temperature at the correlation period. The leave-one-out cross-validation test yielded a positive RE (0.276), indicating predictive skill of the regression model (Table 2). The statistically significant differences between recorded data and leave-one-out-derived estimates detected by ST and Pmt were additional indications of the validity of the 
reconstruction. All of the verification tests indicate that our regression model is reliable and the composite chronology could be used to reconstruct the past history of summer Tmean in the study region.

The annual summer mean temperature records were reconstructed over the past 296 yr (1710 to 2005), as shown in Fig. 7b. These records show that alternating periods of cool and warm conditions were typical of reconstructed temperatures, and the length and amplitude of these temperature cycles varied over time. The mean and standard deviation of the reconstructed values were 8.58 and $0.44{ }^{\circ} \mathrm{C}$, respectively. The reconstruction showed that warm periods prevailed in 1718-1731, 1744-1756, 1781-1790, 1825-1835, 1883-1907, 19301963 , and 1995 to present. Extremely warm years (>1.5 $\mathrm{SD}, 0.665^{\circ} \mathrm{C}$ ) occurred in 1723-1727, 1748-1749, 1751, 1753, 1785, 1933, 1936, 1940-1942, 1944-1945, 19531961, and 2001-2005. In contrast, the following intervals were relatively cold: 1732-1743, 1758-1780, 1791-1824, 1836-1847, 1853-1862, 1908-1929, 1964-1976, and 1979-1993. Extremely cold years $\left(<1.5 \mathrm{SD}, 0.665^{\circ} \mathrm{C}\right)$ were dramatically less frequent than extremely warm years, and were concentrated around the following years: 1799-1800, 1817, 1862, 1866-1867, and 1880.

\subsection{Spectral analysis}

The spectral analysis for the reconstruction revealed significant peaks at the $99 \%$ level in the frequency domains of $0.042,0.047$, and 0.051 , corresponding to the 23.80, 21.32, and 19.68 yr cycles (Fig. 8). The reconstruction also showed peaks at frequencies of 0.014 , $0.088,0.183,0.243,0.271$, and 0.337 , which were significant at the $95 \%$ level for $72.99,11.38,5.48,4.11,3.71$, and 2.97 yr cycles, respectively.

\section{DISCUSSION}

\subsection{The association of tree growth with climate}

Tree-ring data derived from trees sampled at high elevations displayed a strong correlation with summer temperature measurements averaged over large areas of northern America and Eurasia, demonstrating the ability of this proxy to portray summer temperature changes on large scales and across sub-continents (Briffa et al. 2002, 2004, Esper et al. 2002, Osborn \& Briffa 2006, Jones et al. 2007, 2009). In agreement with this reasoning, the chronologies of Abies georgei at the higher elevation sites (BD and YL) in northwestern Yunnan show similar temperature sensitivity in summer (June to August). Conifer tracheids divide and enlarge most actively during the warmest period of the

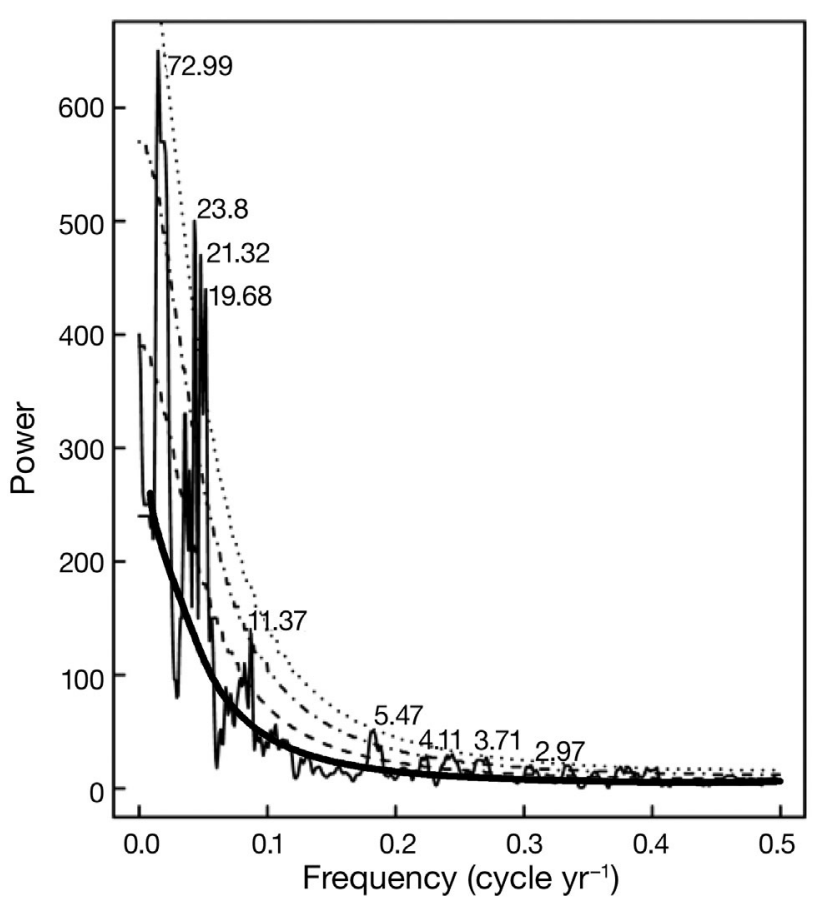

Fig. 8. Multi-taper method (MTM) power spectra of the reconstructed summer temperatures. (bold line) Null hypothesis, (dash) 90\%, (dash-dot) 95\%, and (dotted) 99\% significance levels

growing season, and warm temperatures during this period can promote earlier snowmelt and more rapid warming of soils, thereby increasing the growing season length and resulting in faster leaf, shoot, and stem growth (Körner 1998, Peterson \& Peterson 2001, Deslauriers et al. 2003). In contrast, cold nighttime temperatures in summer not only increase the frequency of frost rings and missing rings, but can also limit the growth of roots and their function in water uptake (Körner \& Paulsen 2004). These negative climatic effects may limit cambial activity by affecting the photosynthetic rate and, hence, the possibility of radial expansion (DeLucia \& Smith 1987). The climatic variable most strongly correlated to radial growth is also summer temperature for the east and northeast Tibetan Plateau (Bräuning 2006), the source region of the Yangtze River (Liang et al. 2008), the central Hengduan Mountains (Fan et al. 2009a, Li et al. 2011a), and the Western Sichuan Plateau (Shao \& Fan 1999, Li et al. 2010, 2011b).

Correlation analysis indicated that spring (April) temperature also has biological relevance for interannual variations in tree growth at the high elevation sites, and similar results have been reported for the Western Himalayas of India and Nepal (Yadav et al. 1997, 1999, Cook et al. 2003). The positive influence of spring temperature on tree growth is evident, as high 
spring temperatures lead to the breaking of dormancy and the resumption of physiological activity in the tree, thus increasing the duration of the current growing season (Lebourgeois et al. 2005). The positive effect of an increase in precipitation and relative humidity in spring (March) on tree growth at low elevation sites can also be related to a direct physiological influence. It is an accepted fact that precipitation decreases from high elevations to low river valleys (Wilson \& Hopfmueller 2001). A moisture deficit might become more prominent at low elevations during the spring season when rainfall is commonly insufficient. Tree growth benefits from spring precipitation, which works directly to increase the soil moisture available during the early part of the growing season and is crucial for tree growth over the next year (Vaganov et al. 1999, Peterson \& Peterson 2001).

There is strong circumstantial evidence that winter temperatures play a major role in modulating mean climate-tree growth relationships. This seems to be a widespread regional phenomena in the high mountains of the Tibetan Plateau and its adjoining areas, including the eastern part of Tibet (Bräuning 2001), the Qaidam Basin near the Qilian Mountains (Liang et al. 2006), the source regions of the Yangtze River (Liang et al. 2008) and the Yellow River (Gou et al. 2007), the western part of the Sichuan Plateau (Wu et al. 2006, Li et al. 2011b), and the central part of the Hengduan Mountains (Fan et al. 2009b). In this study, we also found that winter temperatures are relevant in explaining year-to-year variation in tree-ring widths at the 2 higher elevation sites (Figs. 4 \& 6). However, we also detected a marked difference in signal strength between the temperature variables and the tree-ring data. The tree-ring data showed a statistically significant relationship with the winter maximum temperature $(\mathrm{r}=0.548, \mathrm{p}<0.01)$, followed by mean temperature $(\mathrm{r}=0.337, \mathrm{p}<0.05)$, whereas the weakest correlation was found with minimum temperature ( $\mathrm{r}=$ $0.164, p>0.05)$. This is in contrast to the much stronger correlations with winter minimum temperature found in the central Hengduan Mountains (Fan et al. 2009b) and the source region of Yellow River (Gou et al. 2007). Warm winter conditions notably reduce the frequency of freezing events in winter (Körner \& Paulsen 2004), which are now recognized as a causal factor in tree dieback (Auclair et al. 1996). Additionally, temperate coniferous trees can have a positive carbon gain on warm winter days when their leaves are not frozen (Tardif et al. 2001), and winter carbon availability, as demonstrated by sufficient non-structural carbohydrates (NSC) and the sugar to starch ratio, displays a strong relationship with the survival and growth of coniferous trees in high mountainous areas ( $\mathrm{Li}$ et al. 2008).

\subsection{Changes in reconstructed summer minimum temperatures over time}

Other temperature-sensitive records in the surrounding area allowed us to assess whether our reconstruction represents features that are coherent over a large spatial scale. Our reconstruction mirrored decadal-scale patterns of the reconstructed summer temperatures of the Sygera Mountains in southeast Tibet, China (Liang et al. 2009), based on tree-ring data for a similar fir species at the timberline. The cold episodes found in this study (1791-1824, 1836-1845, 1908-1929, 1964-1975, and 1980-1994) were in agreement with the warm periods occurring in southeast Tibet (1808-1827, 1831-1845, 1888-1933, and 1960-1995). The warm episodes of 1781-1805, 1825-1835, and 1930-1963 prominent in our series also matched fairly well with the warm periods of 1780s-1800s, 1830s, and 1930s-1950s in southeast Tibet. Interestingly, there was an evident discrepancy in between-series coherence in the second half of the 19th century, when our series showed low temperatures from 1853-1882 whereas Liang et al.'s series showed high temperatures from the 1850s-1880s. This could partly result from the potential modulation of local climate conditions.

A comparison of our reconstruction with other records could provide additional support for the spatial synchrony of climate variation. The climate during the 18 th century was relatively warm, characterized by 3 obvious warm periods occurring in 1718-1731, 17441756, and 1781-1790, where 1748-1749 were the extremely warm years. Those warm periods are generally in agreement with the warm conditions from 17051735 and 1775-1790 in the western Sichuan Plateau (Shao \& Fan 1999) and from 1740-1755 and the 1780s in the source region of the Yangtze River (Liang et al. 2008). Based on historical archives, Zhang (2000) also reported an extremely dry and warm period from 1784 to 1787 across a large area of east China, and many snow-rich regions saw no snowfall during this warm event. Temperatures were relatively low from 1809 to 1823, and the coldest year occurred in 1816-1817, with a temperature about 1.5 standard deviations below the long-term mean. This abrupt, extremely cold event in 1816-1817 may be related to the well-documented effect of the Tambora eruption (1815) on temperatures worldwide (Harington 1992, Briffa et al. 1998). There has been increasing tree-ring and ice-core evidence concerning the environmental impacts of the volcanic eruption of Tambora on the Tibetan Plateau and its adjoining regions (Thompson et al. 2000, Liang et al. 2006, Yadav 2007, Fan et al. 2009b). The period of the 1850s-1870s was an apparently prolonged cold period, and strong cool events occurred in the following years: 1862, 1866-1867, 1869-1870, and 1872. This cold pe- 
riod also appeared as a dominant feature in a temperature reconstruction synthesized from stalagmite and tree-ring records from China (Tan et al. 2006).

It is noteworthy that the prolonged cold period in the 20th century occurred in the 1908-1929 period. The incidence of severe cold in the 1910s-1920s is confirmed by tree-ring records and ice cores from the Tibetan Plateau (Bräuning 2006, Singh et al. 2006, Yao et al. 2006). The 1930s-1950s period was a relatively prolonged warm period, which was synchronous with a prolonged warm phase in the Himalayan region (Yadav et al. 1999, Cook et al. 2003) as well as the source region of the Yangtze River (Liang et al. 2008) and the western Sichuan Plateau (Li et al. 2010). The most noteworthy feature in the 20th century was a clear trend of increasing cold intensity in the 1960s1980s. Starting in 1964, the cold intensity increased step by step, especially for the 1965-1966, 1968-1970, and 1983-1989 intervals, and this was also a striking feature of the temperature-sensitive tree-ring data in the adjoining regions (Bräuning 1999, Cook et al. 2003, Yadav et al. 2004, Li et al. 2011b). The 10 most recent years were extremely warm and tree growth was relatively large compared to the earlier part of the 20th century.

\subsection{Significant cycles in the reconstruction}

The cycle of roughly $70 \mathrm{yr}$ in our reconstruction is also present in temperature reconstructions of the eastern margin of the Tibetan Plateau (Shao \& Fan 1999) and the source region of the Yangtze River (Liang et al. 2008). This power spectrum peak is coherent with the centennial-scale Gleissberg cycles (with durations of 70 to 100 yr) of solar activity (Peristykh \& Damon 2003). However, this result should be interpreted with caution, as our tree-ring data only covered several cycles of this periodicity. The bidecadal mode of variation (from 19.68 to $23.8 \mathrm{yr}$ in duration) was most significant in the reconstructed series, and this cycle was strikingly similar in length to the 20 to 23 yr Hale cycle in magnetic solar activity (Lean \& Rind 1998). The existence of a $11.38 \mathrm{yr}$ cycle is consistent with the classic 11 yr sunspot cycle (Shindell et al. 1999), also implying a predominant solar influence. Significant peaks were also found at 5.47, 4.11, 3.71, and $2.97 \mathrm{yr}$, indicating the presence of El Niño Southern Oscillation (ENSO)-type variability (Bradley et al. 1987, Allan et al. 1996), which has a classical bandwidth of 2 to 8 yr. This finding is consistent with the emerging body of dendroclimatological literature suggesting a strong teleconnection between ENSO and interannual variability of tree growth in the Tibetan Plateau (Fan et al. 2008, Liang et al. 2008, Li et al. 2010).

\section{CONCLUSIONS}

In this paper, we developed a tree ring-width series from Abies georgei at 3 sites of different elevation in the Baimang Snow Mountains of northwestern Yunnan, where high-resolution climate proxies are limited. Temperature conditions, especially in the summer season, are shown to be the underlying cause of radial growth at high elevation sites, while moisture availability in spring is crucial for radial growth variation at low elevation sites. A derived linear climate-growth model based on the composite chronology can account for $33.4 \%$ of the summer (June to August) mean temperature. Based on this model, summer temperature variations were reconstructed for the past $296 \mathrm{yr}$. The reconstruction revealed that warm episodes occurred in 1718-1731, 1744-1756, 1781-1790, 1825-1835, 18831907, 1930-1963, and 1995 to present, while the intervals occurring in 1732-1743, 1758-1780, 1791-1824, 1836-1847, 1853-1862, 1908-1929, 1964-1976, and 1979-1993 were relatively cold. The agreement in lowfrequency variations between the reconstruction and temperature-sensitive tree-ring series and ice-core records of the nearby regions confirmed the reliability of our reconstruction. However, the spatial and temporal climate variability of the past several centuries in northwestern Yunnan should be resolved through expanded and improved tree-ring networks in the future.

Acknowledgements. This research was supported by the National Natural Science Foundation of China Project 40631002 and 40890051, and by the Chinese Academy of Sciences Project KSCX-YW-Z-1022. We thank the Forestry Bureaus of Deqin and Weixi for giving much support to our field work. We also thank Mrs. H. Y. Qiu for help in the crossdating of tree-ring cores and Dr. Y. Lu for valuable suggestions and comments regarding the data analysis, which led to an improved manuscript.

\section{LITERATURE CITED}

Allan RJ, Lindesay J, Parker DE (1996) El Niño-Southern Oscillation and climatic variability. CSIRO Publishing, Melbourne

Auclair AND, Lill JT, Revenga C (1996) The role of climate variability and global warming in the dieback of Northern Hardwoods. Water Air Soil Pollut 91:163-186

Biondi F, Waikul K (2004) DendroClim2002: a C++ program for statistical calibration of climate signals in tree-ring chronologies. Computat Geosci 30:303-311

Bradley RS, Diaz HF, Kiladis GN, Eischeid JK (1987) ENSO signal in continental temperature and precipitation records. Nature 327:497-501

Bräuning A (1999) Dendroclimatological potential of droughtsensitive tree stands in Southern Tibet for the reconstruction of the monsoonal activity. IAWA J 20:325-338

Bräuning A (2001) Combined view of various tree ring parameters from different habitats in Tibet for the reconstruction of seasonal aspects of Asian Monsoon variability. 
Palaeobotanist 50:1-12

Bräuning A (2006) Tree-ring evidence of 'Little Ice Age' glacier advances in southern Tibet. Holocene 16:369-380

Briffa KR, Jones PD, Schweingruber FH, Osborn TJ (1998) Influence of volcanic eruptions on Northern Hemisphere summer temperature over the past 600 years. Nature 393: 450-455

Briffa KR, Osborn TJ, Schweingruber FH, Jones PD, Shiyatov SG, Vaganov EA (2002) Tree-ring width and density data around the Northern Hemisphere. I. Local and regional climate signals. Holocene 12:737-757

Briffa KR, Osborn TJ, Schweingruber FH (2004) Large-scale temperature inferences from tree rings: a review. Global Planet Change 40:11-26

Charles CD, Hunter DE, Fairbanks RG (1997) Interaction between the ENSO and the Asian monsoon in a coral record of tropical climate. Science 277:925-928

Cook ER (1987) The decomposition of tree-ring series for environmental studies. Tree-Ring Bull 47:37-59

Cook ER, Kairiukstis LA (1990) Methods of dendrochronology. Kluwer Academic Press, Netherlands

Cook ER, Peters K (1981) The smoothing spline: a new approach to standardizing forest interior tree-ring width series for dendroclimatic studies. Tree-Ring Bull 41:45-53

> Cook ER, Peters K (1997) Calculating unbiased tree-ring indices for the study of climatic and environmental change. Holocene 7:361-370

Cook ER, Briffa KR, Jones PD (1994) Spatial regression methods in dendroclimatology: a review and comparison of 2 techniques. Int J Climatol 14:379-402

Cook ER, Briffa KR, Meko DM, Graybill DA, Funkhouser G (1995) The segment length curse in long tree-ring chronology development for paleoclimatic studies. Holocene 5: 229-237

Cook ER, Meko DM, Stahle DW, Cleaveland MK (1999) Drought reconstructions for the continental United States. J Clim 12:1145-1162

> Cook ER, Krusic PJ, Jones PD (2003) Dendroclimatic signals in long tree-ring chronologies from the Himalayas of Nepal. Int J Climatol 23:707-732

> Cook ER, Anchukaitis KJ, Buckley BM, D'Arrigo RD, Jacoby GC, Wright WE (2010) Asian Monsoon failure and megadrought during the last millennium. Science 328: 486-489

DeLucia EH, Smith WK (1987) Air and soil temperature limitations on photosynthesis in Engelmann spruce during summer. Can J For Res 17:527-533

> Deslauriers A, Morin H, Begin Y (2003) Cellular phenology of annual ring formation of Abies balsamea in the Quebec boreal forest (Canada). Can J For Res 33:190-200

Esper J, Cook ER, Schweingruber FH (2002) Low-frequency signals in long tree-ring chronologies for reconstructing past temperature variability. Science 295:2250-2253

Fan ZX, Bräuning A, Cao KF (2008) Tree-ring based drought reconstruction in the central Hengduan Mountains region (China) since A.D. 1655. Int J Climatol 28:1879-1887

Fan ZX, Bräuning A, Bao Y, Cao KF (2009a) Tree ring densitybased summer temperature reconstruction for the central Hengduan Mountains in southern China. Global Planet Change 65:1-11

Fan ZX, Bräuning A, Cao KF, Zhu SD (2009b) Growth-climate responses of high-elevation conifers in the central Hengduan Mountains, southwestern China. For Ecol Manage 258:306-313

Fritts HC (1976) Tree rings and climate. Academic Press, New York

Gaetz R (2002) Great rivers of Yunnan: conservation in a changing China. Nat Conserv Mag 49:10-17

Gou XH, Chen FH, Jacoby G, Cook E, Yang MX, Peng HF, Zhang Y (2007) Rapid tree growth with respect to the last 400 years in response to climate warming, northeastern Tibetan Plateau. Int J Climatol 27:1497-1503

Harington CR (1992) The year without a summer? Canadian Museum of Nature, Ottawa

Holmes RL (1983) Computer-assisted quality control in treering dating and measurement. Tree-ring Bull 43:69-78

Jones PD, Osborn TJ, Briffa KR (1997) Estimating sampling errors in large-scale temperature averages. J Clim 10: 2548-2568

Jones PD, Briffa KR, Osborn TJ, Lough JM and others (2009) High-resolution palaeoclimatology of the last millennium: a review of current status and future prospects. Holocene 19:3-49

Körner C (1998) A re-assessment of high elevation treeline positions and their explanation. Oecologia 115:445-459

Körner C, Paulsen J (2004) A world-wide study of high altitude treeline temperatures. J Biogeogr 31:713-732

Kumar KK, Rajagopalan B, Cane MA (1999) On the weakening relationship between the Indian monsoon and ENSO. Science 284:2156-2159

Lean J, Rind D (1998) Climate forcing by changing solar radiation. J Clim 11:3069-3094

Lebourgeois F, Breda N, Ulrich E, Granier A (2005) Climatetree-growth relationships of European beech (Fagus sylvatica L.) in the French Permanent Plot Network (RENECOFOR). Trees (Berl) 19:385-401

Li MH, Xiao WF, Shi PL, Wang SG and others (2008) Nitrogen and carbon source-sink relationships in trees at the Himalayan treelines compared with lower elevations. Plant Cell Environ 31:1377-1387

Li ZS, Liu GH, Zhang QB, Hu CJ, Luo SZ, Liu XL, He F (2010) Tree ring reconstruction of summer temperature variations over the past 159 years in Wolong National Natural Reserve, western Sichuan, China. Chin J Plant Ecol 34: 628-641 (in Chinese with English abstract)

Li ZS, Zhang QB, Ma KP (2011a) Tree-ring reconstruction of summer temperature for A. D. 1530-2003 in the central Hengduan Mountains, Northwestern Yunnan, China. Clim Change (in press) doi:10.1007/s10584-011-0111-z

Li ZS, Liu GH, Fu BJ, Hu CJ, Luo SZ (2011b) Tree-ring based summer temperature reconstruction over the past 200 years in Miyaluo of western Sichuan, China. Quat Sci 31: 522-534 (in Chinese with English abstract)

> Liang EY, Shao XM, Eckstein D, Huang L, Liu XH (2006) Topography- and species-dependent growth responses of Sabina przewalskii and Picea crassifolia to climate on the northeast Tibetan Plateau. For Ecol Manage 236:268-277

Liang EY, Shao XM, Qin NS (2008) Tree-ring based summer temperature reconstruction for the source region of the Yangtze River on the Tibetan Plateau. Global Planet Change 61:313-320

Liang EY, Shao XM, Xu Y (2009) Tree-ring evidence of recent abnormal warming on the southeast Tibetan Plateau. Theor Appl Climatol 98:9-18

Liu Q, Wu Y, He H, Wu N, Bao WK (2001) Community characteristics of Abies georgei forest on the western slope of Baima Snow Mountain in northwestern Yunnan. J Chongqing Norm Univ 18:9-14 (Natural Science Edition) (in Chinese with English abstract)

Ma YM, Song ZS, Gao DY (1993) The study of heat balance and moisture budget over the south and central part of Hengduan Mountains in China during the summer of 1985. Plateau Meteorol 12:264-273 (in Chinese with English Abstract) 
Mann ME, Lees JM (1996) Robust estimation of background noise and signal detection in climatic time series. Clim Change 33:409-445

Mann ME, Zhang ZH, Hughes MK, Bradley RS, Miller SK, Rutherford S, Ni FB (2008) Proxy-based reconstructions of hemispheric and global surface temperature variations over the past two millennia. Proc Natl Acad Sci USA 105: 13252-13257

Michaelsen J (1987) Cross-validation in statistical climate forecast models. J Clim Appl Meteorol 26:1589-1600

Myers N, Mittermeier RA, Mittermeier CG, da Fonseca GAB, Kent J (2000) Biodiversity hotspots for conservation priorities. Nature 403:853-858

> Osborn TJ, Briffa KR (2006) The spatial extent of 20th-century warmth in the context of the past 1200 years. Science 311: 841-844

Osborn TJ, Briffa KR, Jones PD (1997) Adjusting variance for sample size in tree-ring chronologies and other regional mean time series. Dendrochronologia 15:89-99

Peristykh AN, Damon PE (2003) Persistence of the Gleissberg 88 -year solar cycle over the last $\sim 12,000$ years: Evidence from cosmogenic isotopes. J Geophys Res 108:1003. doi: 10.1029/2002JA009390

Peterson DW, Peterson DL (2001) Mountain hemlock growth responds to climatic variability at annual and decadal time scales. Ecology 82:3330-3345

Schweingruber FH (1996) Tree rings and environment. Dendroecology Haupt, Bern

Shao XM, Fan JM (1999) Past climate on west Sichuan Plateau as reconstructed from ring-widths of Dragon Spruce. Quat Sci 19:81-89 (in Chinese with English abstract)

Shindell D, Rind D, Balachandran N, Lean J, Lonergan P (1999) Solar cycle variability, ozone, and climate. Science 284:305-308

Singh J, Park WK, Yadav RR (2006) Tree-ring-based hydrological records for western Himalaya, India, since A.D. 1560. Clim Dyn 26:295-303

Stokes MA, Smiley TL (1968) An introduction to tree-ring dating. University of Chicago Press, Chicago

Tan M, Shao XM, Liu HB, Cai BG (2006) A 1000-year temperature record synthesized by combining stalagmite and tree rings from China. Adv Clim Change Res 2:113-116 (in Chinese with English abstract)

Tardif J, Brisson J, Bergeron Y (2001) Dendroclimatic analysis of Acer saccharum, Fagus grandifolia, and Tsuga canadensis from an old-growth forest, southwestern Quebec. Can J For Res 31:1491-1501

> Thompson LG, Yao T, Mosley-Thompson E, Davis ME, Henderson KA, Lin PN (2000) A high-resolution millennial record of the South Asian Monsoon from Himalayan ice cores. Science 289:1916-1919

Vaganov EA, Hughes MK, Kirdyanov AV, Schweingruber FH, Silkin PP (1999) Influence of snowfall and melt timing on tree growth in subarctic Eurasia. Nature 400: 149-151

Editorial responsibility: Tim Sparks, Cambridge, UK
Wigley TM, Briffa KR, Jones PD (1984) On the average value of correlated time series, with applications in dendroclimatology and hydrometeorology. J Clim Appl Meteorol 23: 201-213

Wilson RJS, Hopfmueller M (2001) Dendrochronological investigations of Norway spruce along an elevational transect in the Bavarian Forest, Germany. Dendrochronologia 19:67-79

Wilson R, Tudhope A, Brohan P, Briffa K, Osborn T, Tett S (2006) Two-hundred-fifty years of reconstructed and modeled tropical temperatures. J Geophys Res 111:C10007. doi:10.1029/2005JC003188

Wong MHG, Duan CQ, Long YC, Luo YM, Xie GQ (2010) How will the distribution and size of subalpine Abies georgei forest respond to climate change? A study in northwest Yunnan, China. Phys Geogr 31:319-335

Wu P, Wang LL, Huang L (2006) A preliminary study on the tree-ring sensitivity to climate change of five endemic conifer species in China. Geogr Res 25:43-52 (in Chinese with English abstract)

Wu XD, Lin ZY, Sun L (1988) A preliminary study on the climatic change of the Hengduan Mountains area since 1600 A.D. Adv Atmos Sci 5:437-443 (in Chinese with English abstract)

Wu ZY (1987) Vegetation of Yunnan. Science Press, Beijing (in Chinese)

Xu JC, Wilkes A (2004) Biodiversity impact analysis in northwest Yunnan, southwest China. Biodivers Conserv 13: 959-983

Xu XD, Miao QJ, Wang J, Zhang XJ (2003) The water vapor transport model at the regional boundary during the Meiyu Period. Adv Atmos Sci 20:333-342 (in Chinese with English abstract)

Yadav RR (2007) Basin specificity of climate change in western Himalaya, India: tree-ring evidences. Curr Sci 92: 1424-1429

Yadav RR, Park WK, Bhattacharyya A (1997) Dendroclimatic reconstruction of April-May temperature fluctuations in the western Himalaya of India since A.D. 1698. Quat Res 48: 187-191

Yadav RR, Park WK, Bhattacharyya A (1999) Spring-temperature variations in western Himalaya, India, as reconstructed from tree-rings: AD 1390-1987. Holocene 9:85-90

Yadav RR, Park WK, Singh J, Dubey B (2004) Do the western Himalayas defy global warming? Geophys Res Lett 31: L17201, doi:17210.11029/12004GL020201

Yao TD, Qin DH, Xu BQ, Yang MX and others (2006) Temperature change over the past millennium recorded in ice cores from the Tibetan Plateau. Adv Clim Change Res 2: 99-103 (in Chinese with English abstract)

Ying JS (2001) Species diversity and distribution pattern of seed plants in China. Biodivers Sci 9:393-398 (in Chinese with English abstract)

Zhang DE (2000) 1784-1787 drought occurrence over east China in a warm climatic background. Acta Geogr Sin 55: 106-112 (in Chinese with English abstract)

Submitted: November 15, 2010; Accepted: May 2, 2011 Proofs received from author(s): July 11, 2011 